\title{
POLÍTICA EDUCACIONAL: IDENTIDADE LATINOAMERICANA E DESCENTRALIZAÇÃO
}

\author{
Roseana Costa Leite ${ }^{1}$
}

\section{Resumo}

Esta comunicação tem por objetivo apresentar para discussão um projeto de pesquisa, que pretendo desenvolver como parte das atividades de pós-doutorado, na expectativa de encontrar interlocutores.

Neste momento, minha atenção volta-se às perguntas assinaladas pelos movimentos sociais, à necessidade de praticar uma abertura nos limites da ciência eurocêntrica e da construção de uma cosmovisão alternativa ao ideário neoliberal. A pergunta central refere-se à democratização da política educacional e, nesta discussão, a participação da sociedade civil e as formas de participação direta. Para tanto pretendo examinar a sociologia latinoamericana para estudar a questão da identidade latinoamericana, a partir do conceito de ressentimento social, e a participação social e popular. Esta parte dos estudos pretende representar uma contribuição à discussão a respeito do multiculturalismo e educação. Outro ponto de meu interesse refere-se à questião da descentralização das políticas públicas, no contexto da reforma do estado no atual proceso de reestruturação capitalista, e de seu par complementar a globalização. O suposto é de que a descentralização é una estratégia para limitar la transnacionalização da ação política.

Introdução

Esta comunicação tem por objetivo apresentar para discussão um projeto de pesquisa, que pretendo desenvolver como parte das atividades de pós-doutorado, na expectativa de que possíveis contribuições permitam aprofundar ou corrigir rumos e na esperança de encontrar interlocutores.

Neste momento de definição de uma nova investigação minha atenção volta-se às perguntas assinaladas pelos movimentos sociais, à necessidade de praticar uma abertura aos limites da ciência eurocêntrica e de construção de uma cosmovisão alternativa ao ideário neoliberal. A pergunta central em meus estudos refere-se à democratização da política educacional e nesta discussão interessa-me a participação da sociedade civil e as formas de participação direta. Para tanto pretendo examinar a sociologia latinoamericana para tentar refletir sobre a questão da identidade latinoamericana, a partir do conceito de ressentimento social, e estudar a participação social e popular. Esta parte dos estudos pretende representar uma contribuição à discussão a respeito do multiculturalismo e educação. Outro ponto de meu interesse refere-se à questião da descentralização das políticas públicas, no contexto da reforma do estado no atual proceso de reestruturação capitalista, e de seu par complementar a globalização. O suposto é de que a descentralização é uma estratégia para limitar la transnacionalização da ação política.

A temática sobre o multiculturalismo conquista o espaço acadêmico por força dos movimentos sociais e suas lutas por direitos sociais. No campo educacional, as reflexões que provoca espraiam-se pelas áreas do currículo, da política, da formação docente, da organização escolar, da didática, entre outras. Tema recente, entretanto,

\footnotetext{
${ }^{1}$ Professora Assistente-Doutora do Departamento de Ciências da Educação da FCL/UNESP/Campus Araraquara/SP.rocleite@uol.com.br
} 
encontra-se em processo de construção enquanto aporte teórico com aprofundamento de reflexões e penetração em várias áreas.

As reflexões que tem possibilitado para os estudos sobre a política educacional, enquanto política social, incluem a recuperação histórica de um passado nebuloso, que não nega, mas escreve a história de uma cultura, no caso a cultura latino-americana e mais especificamente a brasileira, a partir de uma perspectiva dominante: o homem branco europeu com posses. O significado deste reconhecimento abre-se para a possibilidade da defesa de uma educação específica para as culturas minoritárias, que valorize e divulgue a cultura específica, e também para a possibilidade de vislumbrar uma outra organização social, enquanto perspectiva de um futuro inclusivo, humano e integrado.

Se a mundialização do capital (Chesnais, 1996) representa a penetração do capital em todas as esferas da vida social globalmente, ao mesmo tempo significa a localização (Beck, 2003), na medida em que os efeitos dessa presença altera os modos locais de vida social.

Se o processo de modernização em curso, segundo a matriz weberiana, constrói, como denuncia a filosofia crítica, a sociedade administrada sob os efeitos da mercantilização de todas as esferas sociais e o mundo se transforma num imenso mercado, onde pode mais quem paga mais, há que se perguntar sobre o porquê da adoção inquestionável de um processo, que conduz a um objetivo que se mostrou inviável. Ou seja, adotamos a melhor maneira, racional, eficiente, eficaz de construir um projeto de futuro que visa o desenvolvimento econômico acima de tudo, acima da integridade da natureza, do homem, da sobrevivência das espécies e dos recursos naturais, da ética, da vida. Este projeto encontra-se esgotado e, mais, já não há controle sobre os riscos causados por este processo de produção e organização da vida em sociedade (Giddens, 1991).

Portanto, se pretendemos refletir sobre o processo de modernização, que constrói um projeto de modernidade, torna-se imprescindível pensar sobre as possibilidades de um novo projeto de futuro, uma modernidade inclusiva em que prepondere a harmonia entre a natureza e os homens.

Os movimentos sociais latinoamericanos estão apontado caminhos para a construção de união mundial em nome do reconhecimento da identidade, da cultura e da tradição indígenas, mas aberta à associação com as causas dos despossuídos. Esta luta alcançou foro mundial pela resistência dos índios peruanos, bolivianos, equatorianos e pelos zapatistas, de Chiapas, México. A possibilidade de construção de um outro futuro não há de sair do bolso do colete, a recuperação de uma história, cujas raízes perduram e florescem comunidades que a mantém viva, merece atenção e estudos.

No Brasil, o reconhecimento e valorização dos povos índios vai, lentamente, se fortalecendo na vida social e no meio acadêmico, ao lado do fortalecimento do movimento sobre a consciência negra, que tem garantido conquistas mas, em tempos neoliberais, tem se traduzido pela política de cotas no sistema educacional e público, e do Movimento dos Sem Terra, MST, que tem impulsionado as lutas no campo e nas cidades.

Uma perspectiva para a análise das políticas educacionais, sob a perspectiva da democratização $^{2}$ da educação, é oferecida pelo acompanhamento e estudo da educação de jovens e e adultos, parcela da população que esteve fora do sistema

\footnotetext{
${ }^{2}$ Por democratização da educação entende-se a participação ampliada e direta da população na definição da política educacional, suas diretrizes básicas e financiamento, e na forma de sua implementação.
} 
formal de educação e, por um ou outro motivo, encontra-se em alguma situação de exclusão, inclusive das preocupações e do atendimento pelo sistema educacional público, consistindo mais em área da assistência social e do voluntariado comunitário ou religioso.

O financiamento educacional tem-se focalizado no ensino fundamental (oito séries) regular na idade correta (7 a 14 anos) e para os demais níveis (infantil, préescola, médio, supletivo ou EJA) os municípios e estados devem manter com o restante da verbas insuficientes. Além de projetos focalizados social e geograficamente e da política de cotas para negros, índios e estudantes de escola pública, pouco ou nada há para se pensar em sistemas públicos alternativos, que contemplem diferentes culturas e identidades.

Além disso, o trabalho com o processo de ensino-aprendizagem em salas de educação de jovens e adultos suscita reflexões, dentre as quais destaco a construção ou o resgate da auto-estima que este processo desencadeia. Refiro-me a uma população que sente a exclusão econômica e social, a exclusão de uma sociedade letrada e carrega a culpa por essa situação, percebem-se pessoalmente responsáveis pelo seu destino, assim lhes foi ensinado, e não questionam a ordem social vigente. Estas pessoas tentam afastar a lembrança de uma situação de violência simbólica ou não; diante da qual não souberam ou não puderam reagir. Esta impotência ou covardia detona uma mágoa sempre revivida, como vítima. São àqueles a quem a promessa da República não atingiu, àqueles que não obtiveram o estatuto da cidadania e que assumem uma valorização negativa de sua identificação, a partir de características cultural, geográfica, de raça, entre outras. A consequiência disto é a paralisia política. Os acontecimentos traumáticos vividos por um grupo minoritário não podem ser esquecidos pela sociedade, sob pena destes nunca poderem se poderar da história como sujeitos (Kehl, 2004).

Sabemos que a educação de jovens e adultos atinge resultados para além do processo de letramento ou alfabetização e envolve a questão da qualidade de vida dos educandos, ou seja seus hábitos e seu modo de interpretar a si mesmo e ao mundo.

A referência teórica para o estudo e o desenvolvimento de atividades na educação de jovens e adultos, Paulo Freire, traz a preocupação com o registro cultural dos educandos jovens e adultos. Uma das diretrizes centrais da concepção freiriana de educação prevê o reconhecimento do universo lingüístico dos componentes da turma que expõe os elementos de significação da vida daqueles homens e mulheres, as referências de seu trabalho, valores, relações sociais, consciência política, etc. Partir do conhecido, relembrar o conhecimento histórico e social para ampliar a leitura de mundo dos componentes do grupo constitui-se um projeto social e cultural, que contempla aspectos de uma política educativa multicultural, digamos assim. Outra perspectiva a ser considerada na elaboração de uma tal política diz respeito à educação ecológica, segundo as formulações de Capra e Huntington, que centraliza no processo educacional o debate sobre uma nova relação entre homem e natureza, não mais de domínio daquele sobre esta senão de harmonia entre elementos interdependentes. Cosmovisão que figura entre as culturas indígenas relegadas pelo olhar indulgente do progresso, diante do ingênuo e a-científico, ao esquecimento.

$\mathrm{E}$, neste ponto, retornamos a um tema colocado no início desta exposição, a mundialização do capital, para apontar uma questão que desvela um encaixe feito de oposição e complementaridade. Refiro-me ao conjunto de idéias liberais que prega a desregulamentação da economia, as privatizações dos sistemas e empresas públicos, o livre-mercado como solução, o mundo como arena do capital. E ao mesmo tempo, por meio das agências financeiras multilaterais determina os ajustes estruturais 
necessários à condução do único projeto político-econômico possível para o processo de modernização, rumo à conquista de posições no mercado internacional. Oculta-se, entretanto, que este mercado encontra-se fatiado e esta posição já está marcada. A produtividade, a eficiência e eficácia do sistema público, ou seja o custo-benefício como critério único da administração tal como as regras mercadológicas, devem ser as diretrizes centrais, aliadas a duas outras metas, entendidas como meio para a consecução de tais diretrizes, a modernização do sistema público, entendida como informatização de toda a administração, e a descentralização das políticas sociais.

A descentralização política figura entre os grandes temas dos partidos e sindicatos comprometidos com o processo de democratização, dos movimentos e lutas sociais e populares e significa a luta pelo poder, pela participação direta na definiçãa e implementação das políticas públicas. Mas neste novo ideário, que varre o mundo desde o final do século passado, travestida como o trinômio descentralizar-participarmelhorar, descentralização significa empurrar a responsabilidade e os custos para o local e aliviar a pressão social no centro do sistema, além disto fiscalização chama-se participação e a qualidade é o resultado da competição entre as instituições pelos poucos recursos existentes, que são disputados pela apresentação de projetos. A pulverização de protestos dificulta a organização de amplos movimentos de massa dirigidos ao centro do sistema público, que ainda responde somente em nível nacional, na medida em que toda a responsabilidade concentra-se nas Prefeituras dos municípios. Enquanto isso, o capital age mundialmente determinando, inclusive, esses níveis locais.

Estas considerações servem para indicar a necessidade de recompor significados e criar alternativas que revertam o caminho do isolamento condicionado pelo movimento de descentralização atual.

Desenvolvimento: delimitação do problema

Os sociólogos clássicos, segundo Beck (2004), a partir das observações da realidade européia dos séculos XIX e início do XX, difundiram um modelo conceitual de sociedade e impulsionaram a colonização de outras regiões do mundo de acordo com esta perspectiva sociológica. Atualmente, esta conceituação prescritiva da sociedade já não coincide com o recipiente social tal como o conceberam os sociólogos ocidentais.

Assim, consideramos a importância de estudos que, tendo como questão central a educação enquanto fenômeno social, considerem as características das ciências sociais latinoamericanas, nos diferentes momentos históricos, os referenciais teóricos que as sustentam, seu caráter atual, a fim de recuperar esta memória teórica e explorar novas categorias, diante da necessidade de se repensar a América Latina, no contexto da globalização.

Neste sentido, pretendemos também estudar o discurso índio na América Latina, suas características principais, o marco histórico em que surge e sua situação diante do processo de mundialização do capital. Mais especificamente, trata-se de comparar os movimentos andinos e zapatista pela dignidade indígena, analisar o caráter destes movimentos, seu contexto histórico, suas utopias e refletir sobre suas contribuições para o pensamento social latinoamericano e para a construção de um projeto alternativo de futuro.

Em relação à mundialização do capital, importa ainda aprofundar as reflexões sobre a descentralização, enquanto processo correlato e complementar e uma das diretrizes centrais das orientações das agências financeiras multilaterais para as 
políticas sociais dos países latinoamericanos e que tem sido adotada pelos governos destes países, a partir principalmente da década de 1990.

Sobre a presença das agências internacionais no Brasil e sua influência sobre a política educacional brasileira, desde 1950, assistimos a penetração do capital estrangeiro na área educacional, pelos convênios firmados entre Brasil e Estados Unidos, os famosos Acordos MEC-USAID Vieira (2001) compara a época de 60 à década de 90, quando novamente o fluxo de acordos internacionais intensifica-se, bem como a centralidade do campo educacional. Em relação a este último tema identifica três variáveis que contribuíram para o destaque da educação. A primeira está ligada à construção de uma agenda internacional para a educação realizada numa série de eventos por declarações de intenções e recomendações, ${ }^{3}$; a segunda variável relaciona-se a retomada de uma concepção que articula educação e desenvolvimento semelhante à teoria do capital humano, acoplada ao entendimento do papel importante da educação na definição de um cenário mundial, denominado como a revolução do conhecimento; e, finalmente, a terceira refere-se à presença de organizações internacionais no país voltadas para o desenvolvimento de projetos na área de educação, como o Banco Mundial.

Percebemos como complementares os processos de globalização e descentralização, pois, como argumenta Beck (2004), globalização não significa que tudo ocorra em instâncias superiores, e sim que ela passa a ter repercussão local, inclusive nos lugares mais remotos. Diz: globalização não é globalização, e sim transnacionalização; e sim localização. Ou seja, com a globalização, o local se valorizou e o conceito de globalização é impensável sem localização.

Alerta para o fato de que continua existindo a necessidade de se localizar e de que a globalização é um processo dialético que realça um novo significado ao local. Assim , reconhece uma tendência do desenvolvimento de massificação do mundo, mas compensada pelo novo significado do local. Isto significa não apenas a necessidade de adaptação das empresas globais à localidade nas quais se instalam, mas também que o local adquire um novo reconhecimento e uma força fomentadora de identidade.

$\mathrm{Ou}$, em outras palavras,

não se deve conceber a globalização linearmente, e sim dialética e reflexivamente. Até agora, ao lado da homogeneização, têm surgido também a multiplicação e a diferença.. (p.53)

Partimos do pressuposto, entretanto, de que os processos de descentralização em curso na região, longe de permitir ou fomentar um novo reconhecimento do local e a construção da identidade, tem servido para pulverizar a mobilização e força de movimentos políticos que se oponham ao conjunto das políticas sociais e a diretrizes específicas destas. O processo revela-se, portanto, essencial para aliviar a pressão à esfera central do governo $\mathrm{Ou}$ seja, o capital financeiro faz-se representar mundialmente por instituições sociais reconhecidas e não quer que as demandas legítimas da população possam se expressar sequer na instância federal. A descentralização, nos moldes em que vem sendo implementada, visa dificultar a criação de laços ou redes que facilitem a articulação dos interesses dos setores desfavorecidos da sociedade e sua organização em movimentos que englobem diferentes aspectos e instâncias. Ao contrário tem possibilitado uma forma mais eficiente e eficaz, ou seja de menor custo e mais rápida, de controle das metas e diretrizes estabelecidas centralmente para as políticas sociais. E mais empurra-se para

\footnotetext{
${ }^{3}$ Tais como: Conferência Mundial de Educação para Todos (Jontien, 1990); Conferência de Nova Dlhi (1993); e Conferência de Kingston (1996).
} 
as localidades ou comunidades a responsabilidade sobre as formas de financiamento, obrigando-as a concorrer pelos insuficientes recursos federais no balcão dos projetos apresentados, que são atendidos segundo critérios clientelista e de adesão às metas já estabelecidas. Com um vantajoso adicional, a culpa pelos recursos insuficientes ou precário atendimento das demandas sociais será da própria localidade ou comunidade, que se transforma, assim, de vítima a algoz.

Para Beck a globalização representa um novo desdobramento global do poder e o fim de uma concepção da política organizada em termos territoriais e de Estado nacional, na disputa de poder entre capital, Estado e trabalho. $\mathrm{Na}$ globalização a economia adquiriu o poder de subtrair-se, de abandonar o jogo do poder territorial, pode desterritorializar o conceito de poder. A não-intervenção intencional, desprovida de violência, torna-se a base do poder econômico que obriga Estados bem armados a realizarem, obediente e antecipadamente, as máximas do regime liberal de mercado mundial. (p.43-44)

Temos então não o imperialismo da invasão, com um centro do poder demarcado, mas sim o imperialismo de retirada realizado numa política de fatos consumados que passa ao largo de toda questão de legitimação (p.46). A modernização da política pode ter dois significados: 1) ceder às coerções da globalização econômica e sujeitar a política ao primado da economia sem fronteiras, e aqui o Estado Nacional torna-se uma promessa que nem mesmo ele é capaz de cumprir, ou, 2) sujeitar politicamente a globalização. (p.46)

Lembra que, num mundo cosmopolita, o esvaziamento do contêiner estatal só permanecerá enquanto o Estado for pensado como ação política territorialmente organizada, o que possibilita refletir sobre a viabilidade de agentes políticos desterritorializados, a exemplo da economia, que poderiam representar um perigo sem igual ao capitalismo transnacional sem a proteção de nenhum Estado. Este raciocínio valeria também para a constituição de uma política em que ministérios e repartições cooperassem em rede tendo em vista os interesses de soberania e que o próprio modelo de Estado desenvolvesse rumo a constituição de Estados cooperativos pós-nacionais passíveis de se contrapor aos agentes políticos transnacionais globalizados.

Beck (2004) considera que o vínculo entre globalização e neoliberalismo gera uma forma de globalismo que nivela de diversos modos culturas inteiras, com a conquista e colonização do espaço cultural com o orçamento da publicidade e dos meios publicitários. Este tipo de globalismo,

ou seja, a ideologia segundo a qual o mercado pode resolver todos os problemas, é um dos perigos centrais da cultura democrática da diversidade. Pois esse modo de proceder conduz, em última instância, à idéia de substituir a política pelo mercado. (...) Com isso, eliminar-seiam os requisitos da democracia e da liberdade que até agora, pelo menos no Ocidente, foram cumpridos pelo contêiner do Estado Nacional (p.55)

Longe portanto de fomentar um processo de identidade própria, a realidade que cerca os povos latinoamericanos constrói um processo de individualização. Beck (2004) propõe a expressão individualismo institucionalizado para indicar uma alteração na dinâmica do processo de individualização: a sua institucionalização.

A minha noção de institucionalização fica mais clara se eu começar com a expressão "individualismo institucionalizado". Individualismo institucionalizado significa que não se trata de uma forma de percepção do indivíduo isolado, mas trata-se, isto sim, de instituições centrais da sociedade moderna, como a necessidade de desenvolver uma biografia própria, de se despegar das predeterminações coletivas. (p.68) 
Beck (2004) destaca que a educação, o mercado de trabalho e a mobilidade impulsionaram e mantiveram a individualização e garantiram, portanto, as condições institucionais básicas que têm como ponto de orientação não o coletivo, mas o indivíduo. (p.68)

Essa individualização tem dupla conseqüência, por um lado representa a coerção e o desejo de projetar uma biografia própria em todas as dimensões da vida e que perdure inclusive no casamento e na família; por outro lado isso provoca a dissolução dos modelos tradicionais, das matrizes, de organização do cotidiano, dos deveres atribuídos aos diferentes papéis, dos papéis dos sexos. (p.69)

\section{Em suma,}

Individualização significa, pois, que se entra numa dinâmica institucional endereçada ao indivíduo, não ao grupo. Isso, por sua vez, tem a conseqüência de livrar as pessoas das diretrizes tradicionais acerca do papel dos sexos e da organização da família. Coisa que, de sua parte, impõe decisões, negociações, conflitos, e cuja característica é agora muitos problemas basicamente condicionados pelo institucional são descarregados nos indivíduos.(p.69)

Considera a educação como uma das maiores revoluções ocorridas, ainda que silenciosamente, cujas consequiências só se percebe em parte. A partir dos anos $60 \mathrm{e}$ 70, a expansão da educação, a reforma de ensino e a equiparação de mulheres e homens na educação projetam-se como pano de fundo de um novo impulso à individualização.

Aliás, as situações de confronto sócio-cultural têm sido reforçadas pela globalização e a relação entre educação e cultura, temática que não é recente, vêm se reconfigurando em função destas situações. Candau, 2003 destaca que o campo de estudo sobre as questões multiculturais penetram na academia trazidas pela força dos movimentos sociais (ligados principalmente às questôes identitárias) e lutas de grupos sociais discriminados e excluídos. É mais um tema de militância que propriamente acadêmico.

Duas questões importantes demandam estudos a concepção de cultura predominante nas propostas de educação multicultural e, importa ainda, desvendar as articulações entre as dimensões políticas, sociais e culturais. Como alerta Candau, não podemos reduzir as questões de identidades específicas de culturas e grupos étnicos ao problema da desigualdade social e das relações e conflitos entre classes sociais, como fazem algumas posições marxistas clássicas, nem ampliar de tal forma o conceito de cultura, que este passa a ter um caráter totalizador e de determinação da realidade social.

Outro conceito importante na perspectiva multicultural é o da alteridade e a autora cita três perspectivas sobre a diversidade que animam o imaginário social: $o$ outro como fonte de todo mal, o outro como sujeito pleno de um grupo social e o outro como alguém a tolerar.

A primeira perspectiva marca as relações sociais durante o século XX, em que a alteridade assume a lógica binária, a diversidade cultural deve despir-se de suas marcas identitárias para ser como as demais. O sistema escolar está povoado de oposições binárias, de um lado o legítimo, o desejável, de outro o componente negativo que deve ser descartado.

Quanto `a segunda perspectiva, o problema reside na concepção de cultura representada por uma comunidade homogênea e estática de crenças estilos de vida 0 que suporia encerrar o termo em categorias imóveis e essencialistas. Na educação essa 
perspectiva tem resultado em duas manifestações centrais: "uma entrada folclórica, caracterizada por um percurso turístico de costumes" e como retórica legitimadora de uma pretensa autonomia institucional.

A terceira perspectiva, o outro como alguém a tolerar, supõe a aceitação de grupos cujas marcas são comportamentos anti-sociais e opressivos. No campo educacional resulta numa posição de fugir à polêmica, de evitar que sejam examinados e tomada uma posição em relação aos valores que dominam a cultura contemporânea, assumir a conciliação e inibir o questionamento da ordem.

Assim, Candau reconhece a existência de diferentes tendências, até a oposição entre uma orientação diferencialista e culturalista, com delimitações precisas de universos culturais, até outra que concebe as culturas como fenômenos dinâmicos em contínuo processo de construção, reconstrução, desconstrução e "hibridização". A ênfase, nesse entendimento, é colocado nos lugares de fronteiras, nos lugares de encontro e confronto de tradições, pertencimento e identidades. A importância do debate reside em reconhecer o direito à diferença e a luta contra a discriminação e desigualdade social; promover relações dialógicas e igualitárias entre pessoas e grupos de diferentes culturas; reconhecer as relações de poder nas relações sociais e interpessoais e assumir os conflitos buscando estratégias adequadas para enfrentá-los.

O conceito de hibridização desenvolvido por Canclini (1999), para quem subsistem as diferenças e a tradubilidade entre as culturas é limitada, revela-se rico para a análise, na medida em que considera que, se superarmos as narrativas da homogeneização absoluta e da resistência do local, podemos apreender com a globalização fragmentos de outras culturas, nunca a totalidade, e reelaborar o que vínhamos imaginando como próprio em interações e acordos com outros, nunca com todos.

Pretendemos aprofundar o contato com a literatura sociológica latinoamericana e explorar categorias que possibilitem pensar a realidade social destas sociedades e alternativas para a construção de um projeto que preserve a vida em suas diferentes dimensões. Nesta perspectiva de uma nova construção social, refletir sobre a contribuição da educação, a partir de uma concepção que inclua a diferença e o diferente, e a todos sem distinção nos diversos aspectos das necessidades humanas.

Reconhecer a história emudecida do continente latinoamericano, principalmente a história dos povos que antecedem a chegada dos europeus, enquanto movimento paradigmático de emancipação e resistência. Estudar a questão da identidade, enquanto processo de poder, portanto político, e, mais especificamente deter-me na discussão acerca de uma valorização identitária negativa, presente na formação da latinoamericana, fundamentada no estudo sobre ressentimento social.

Considerar as consequiências teóricas deste debate para o campo educacional, a partir de duas perspectivas, a educação de jovens e adultos e o multiculturalismo.

Estudar o processo educacional no continente, com destaque para a questão da democratização e das formas de participação e, mais especificamente, para os processos de descentralização.

Para a realização desta investigação, além do levantamento e análise bibliográfica referente às temáticas envolvidas no estudo, tentaremos publicações específicas e documentos sobre os movimentos e manifestações sociais pela educação pública, no continente latinoamericano, particularmente México. Equador e Peru, no século XX. Igual atenção receberá a comparação entre os processos de descentralização ocorridos na região, no mesmo período. 
Pretendemos, também, desenvolver a análise das categorias teóricas fundamentais para a realização da pesquisa e tecer uma interpretação da realidade em estudo.

Bibliografia

BECK, U. Liberdade ou capitalismo/Ulrich Beck conversa com Johannes Willms. São Paulo : Editora UNESP, 2003.

CANCLINI, N. G.Culturas híbridas: estratégias para entrar e sair da modernidade. São Paulo : Editora da Universidade de São Paulo, 1997

CANDAU, V. M. Didática e interculturalismo: uma aproximação. In: In:LIMA, V.M. S. SOUSA, L. F. E. Políticas educacionais, práticas escolares e alternativas de inclusão escolar. Rio de Janeiro: DP\&A, 2003.

CASTELLS, M. A sociedade em rede. A era da informação: economia, sociedade e cultura; v. 1. São Paulo : Paz e Terra, 1999.

- $\quad$ O poder da identidade. A era da informação: economia, sociedade e cultura; v. 2. São Paulo : Paz e Terra, 1999

CHESNAIS F. A mundialização do capital. São Paulo : Xamã, 1996, pp.21-44.

KEHL, M. R. Ressentimento. São Paulo : Casa do Psicólogo, 2004.

GIDDENS, A. As conseqüências da modernidade. São Paulo : Editora UNESP, 1991.

VIEIRA, S L. Políticas internacionais e educação - cooperação ou intervenção? In: DOURADO, L.F. PARO, V.H. Políticas públicas e educação básica. São Paulo: Xamã, 2001. 